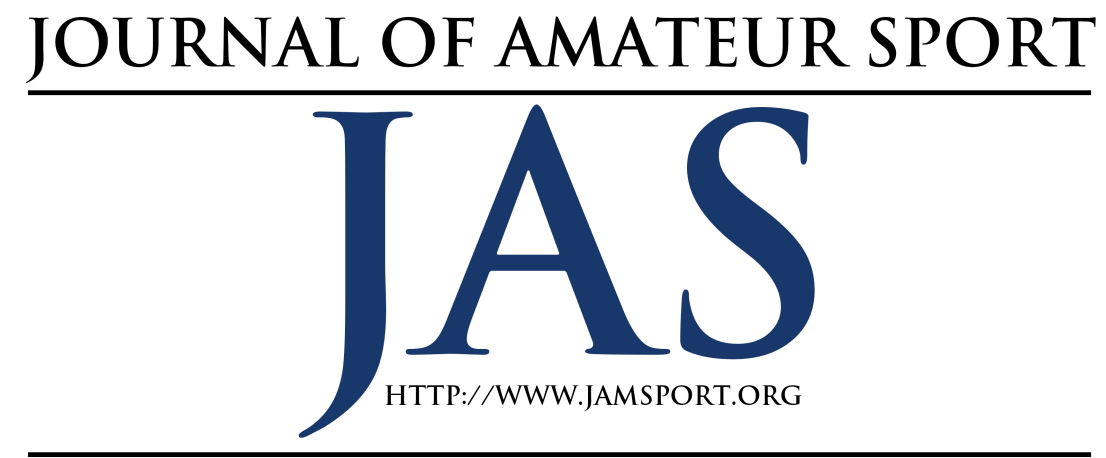

\title{
Psychological Antecedents of Youth versus Adult Participation: An Examination Based on the Sport Commitment Model
}

\author{
Jung-Hwan Jeon ${ }^{1}$ \\ ${ }^{1}$ University of North Carolina-Greensboro \\ Jonathan M. Casper ${ }^{2}$ \\ ${ }^{2}$ North Carolina State University
}

\begin{abstract}
This study examined adult and youth Taekwondo (TKD) participants utilizing the Sport Commitment Model (SCM; Scanlan, Carpenter, Schmidt, Simons, \& Keeler, 1993). TKD participants (adult, $n=205$; youth, $n=227$ ) from four studios completed a questionnaire that included SCM variables (commitment, enjoyment, involvement alternatives, involvement opportunities, personal investments, social constraints, and social support). A multiple-group path analysis compared age groups to assess similarities and differences. Similarities between age groups included enjoyment, involvement opportunities, and personal investments as significant predictors of commitment. Analysis of differences found that involvement alternatives only predicted commitment with adults while social support only predicted commitment with youth. This was the first study examining the SCM with both adults and youth participating in the same sport. Theoretical and practical implications are discussed.
\end{abstract}

S port participation is important for physiological and psychological health (Penedo \& Dahn, 2005). In order to achieve such benefits, continued participation is imperative. Commitment has been used to explain consistent involvement of sport participants (Carpenter \& Coleman, 1998; Casper, Gray,
\& Babkes-Stellino, 2007). Sport-related literature operationalizes sport commitment as a psychological state representing the desire and resolve to continue sport participation in a particular program, specific sport, or sport in general (Scanlan et al., 1993). Past research has found that highly committed sport participants show 
high levels of behavioral involvement and financial investment (Bodet, 2012; Casper et al., 2007; Fernandes, Correia, Abreu, \& Biscaia, 2013; Kim, James, \& Kim, 2013).

Much of the commitment related research in sport has focused on youth participation and the reasons that youth become initially involved and committed to sport (Carpenter \& Coleman, 1998; Weiss, Kimmel, \& Smith, 2001). More recently this has been applied to adult participation (e.g., Casper et al., 2007; Fernandes et al., 2013; Young \& Medic, 2011). While such research helps to understand commitment to a sport, the differences as to why adults versus youth are committed are still unknown. Such differences between developmental ages may help with marketing sport for both recruiting new participants and retention of current participants. Therefore, the purpose of this study is to investigate adults and youth participating in an identical sport, Taekwondo, to understand what key differences (or similarities) are indicative of commitment to the sport.

\section{Theoretical Framework The Sport Commitment Model}

The Sport Commitment Model (SCM: Scanlan et al., 1993) serves as a theoretical framework to understand the nuances of continued sport participation and psychographic information for marketing and recruitment of new participants. Sport commitment is defined as the "psychological state representing the desire and resolve to continue sport participation"
(Scanlan et al., 1993, p. 6). The SCM was adapted from social-exchange theory (Kelley \& Thibaut, 1978), the model of interpersonal relationships (Kelley, 1983), and the investment model (Rusbult, 1988). The purpose of developing the SCM was to have a better understanding of the antecedents of sport commitment. For this study, the SCM was chosen based on three important features: 1) Sport commitment addresses psychological attachment to an activity, and does not involve estimations of the actual probability (e.g., intentions); 2) Sport commitment is a product of both cognitive (e.g., thinking) and affective (e.g., emotions) factors; and 3) the model is able to distinguish differing predictors of participants who may report equal levels of commitment (Scanlan \& Simons, 1992). The model focuses specifically on commitment in addition to the meaning that underlies the commitment that individuals hold for the activities in which they participate. Lastly, the SCM looks at commitment and its antecedents based on theory from sport participation. Thus, the use of the model versus other models of commitment (e.g., organizational or spectatorship) is more theoretically grounded for the population under study (Casper et al., 2007).

\section{Variables in the Model}

The original SCM was posited as having five direct antecedents that can increase or decrease sport commitment: sport enjoyment, involvement alternatives, involvement opportunities, personal 
investments and social constraints (Scanlan et al., 1993). Operational definitions of the predictor variables in the SCM are as follows (Scanlan, Simons, Carpenter, Schmidt, Keeler, 1993):

Sport enjoyment is defined as a positive affective response to the sport experience that reflects generalized feelings such as pleasure, liking, and fun.

Involvement alternatives are defined as the attractiveness of the most preferred alternative(s) to continued participation in the current endeavor.

Involvement opportunities are the anticipated benefits that one receives through continued participation such as friendships, social interaction, skill mastery, and physical conditioning.

Personal investments reflect personal resources such as time, effort, and energy that would be lost if participation did not continue.

Social constraints are the social expectations or norms that create feelings of obligation to remain in the activity.

An additional predictor of sport commitment revealed in recent research, grounded in the SCM, is social support (Scanlan, Russell, Beals, \& Scanlan, 2003; Scanlan, Russell, Wilson, \& Scanlan, 2003).

Social support reflects feelings of encouragement and support that a sport participant receives from significant others who may or may not participate in the sport (Carpenter \& Coleman, 1998).

Among these six antecedent variables, sport enjoyment, involvement opportunities, personal investments, social constraints and social support are hypothesized as positive predictors of sport commitment (i.e., contributes to commitment) while involvement alternatives are posited as negative predictors of sport commitment (i.e., detracts from commitment) (Scanlan et al., 1993).

This study tested direct and indirect paths SCM based on the work of Weiss et al. (2001) and Casper et al., (2007). As theorized by Scanlan et al., many SCM studies with youth found enjoyment was the strongest predictor of commitment (e.g., Stein \& Scanlan, 1992; Scanlan, Ravizza, \& Stein, 1989). When investigating the SCM with youth tennis players, Weiss et al. (2001) modified the original model to further understand the impact of enjoyment. To do this they tested direct/indirect influences of the commitment model to determine if sport enjoyment was indeed masking the effects of the other determinants of sport commitment. Weiss et al. (2001) tested the indirect model and revealed that the indirect model presented a clearer understanding of the other commitment antecedents that were not identified in the direct model. As a follow-up, Casper et al. (2007) compared the direct and indirect models with adult tennis participants and, consistent with Weiss et al. (2001), the indirect model provided a more intricate understanding of sport commitment formation (e.g., personal investment and social constraints emerged as significant predictors). 


\section{Past SCM Research}

In its early phase, the SCM was applied in competitive youth sport domains such as softball and baseball (Scanlan et al., 1993), football, soccer and volleyball (Carpenter et al., 1993), cricket (Carpenter \& Coleman, 1998), and tennis (Weiss et al., 2001).

Further use of the SCM examined adult participants in exercise/fitness area (Alexandris, Zahariadis, Tsorbatzoudis, \& Grouios, 2002), tennis players (Casper et al, 2007), windsurfers (Jeon \& Ridinger, 2009), triathletes (Crocker \& Augaitis, 2010), and masters swimmers (Young \& Medic, 2011). Examination of the results from previous SCM studies shows that antecedents predicting commitment adult participants compared to youth participants vary. For example, studies showed enjoyment is the primary predictor of sport commitment within the youth whereas involvement opportunities are reported as the most significant predictor of sport commitment in adults (Alexandris et al., 2002; Casper et al, 2007; Jeon \& Ridinger, 2009). Additionally past research has found that the latent predictors of sport commitment significantly differ based on sport type (e.g., recreational versus competitive sport). For example, Casper and Andrew (2008) revealed different significant predictors of tennis commitment between recreational players and college athletes. The study found that the collegiate athletes reported lower sport enjoyment levels, but higher levels of involvement opportunities and social constraints, than recreational players.
Casper and Babkes-Stellino (2008) found significant differences predicting commitment based on age and gender. For example, among four age-groups the two youngest groups reported significantly higher involvement alternatives and social constraints than the other two groups, and female participants indicated higher levels of enjoyment and personal investment while males reported higher levels of social support. The findings of these studies are meaningful because in terms of significant predictors of commitment there are differences, in particular age in the same sport.

The differences between youth and adult sport participants may be illuminated by studying both groups in the same sport context. The SCM has examined various adult and youth sport participants separately. However, a thorough literature search has found no research on adult and youth who participate in an identical sport.

\section{Taekwondo}

The sport of Taekwondo (TKD) is a popular global sport with an estimated 80 million participants (WTF, 2015) and serves as an ideal sport to investigate commitment since it is popular with both youth and adults (Kim, Zhang, \& Ko, 2009). Previous studies have found that regular TKD participation can provide physiological (e.g., aerobic capacity, body composition, and flexibility) and psychological health benefits (e.g., life satisfaction, behavioral and social improvements) (Byeon, Kwon, \& Park, 
2008; Fong \& Na, 2011; Kim, Dattilo, \& Heo 2011; Lakes, 2013; Lakes et al., 2013). Motives for participating in TKD with youth include skill mastery, the uniqueness of the sport, fun, and physical benefits (Zeng, Cynarski, Baatz, \& Park, 2015), while adults have reported self-realization and health benefits as primary motives (Ko, Seok, \& Kwon, 2013).

Studying TKD has industry relevance as well since the sport suffers from poor retention of participants. For example, a number of youth drop their participation right after achieving Black-Belt status (Kang, 2004) and decreasing participation has been observed over the past decade with adult participants (Kim et al., 2009; Sport Business Research Network, 2014). Due to decreasing adult participation and poor retention of youth, TKD can be seen as a representative sport to understand commitment at all age levels. Thus, this serves as a seminal study to further academic theory on SCM by examining psychological commitment of two age groups while having practical needs within the industry. Furthermore, the findings may provide valuable information to other amateur and recreation sports faced with similar challenges.

\section{Purpose}

This study examines TKD commitment through the use of the SCM (Scanlan, Carpenter, Schmidt, et al., 1993). The purpose of this study is to investigate adults and youth participating in an identical sport,
Taekwondo, to understand what key differences (or similarities) are predictive of commitment to the sport.

\section{Method \\ Participants and Procedure}

This study was approved by the Institutional Review Board at the researchers' university. Children under 18 years old were required to have the parental permission form completed on the front page of the survey and children under 10 years old were asked to have parents help with reading the questions to ensure comprehension. Adults in the TKD classes were asked to participate in the survey. However, their participation was completely voluntary. Participants for this study were recruited from four TKD studios in the Southeastern United States. Studio members were given the survey at the end of each group lesson and instructors encouraged the members to complete and drop off the questionnaire before they left the building. Each studio was given one week to distribute the surveys to their membership. To encourage participation, each studio provided an incentive (a uniform) as part of a random drawing if survey participants provided their e-mail address at the end of the survey. A total of 700 surveys (based on estimate of number of members) were distributed at the four studios and 434 surveys were collected one week later (response rate $=62 \%)$. Missing values analysis identified three surveys that had over $10 \%$ of the data missing and were omitted (Allison, 2001), leaving 432 surveys 
for further analysis. Full descriptive statistics and frequencies are shown in Table 1.

Youth were coded as respondents who indicated their age was 18 or younger; while adults were coded as those that were 19 and older.

\section{Instrument}

The questionnaire included categorical demographic and behavior items that pertained to gender, gross household income, race, and past participation in TKD (see Table 1). The SCM items were formulated based on previous SCM research on both adult and youth sport participants (e.g., Casper et al., 2007; Scanlan et al., 1993). The questionnaire was pilot tested for clarity, understanding, and time to complete with four youth (ages 8-14 years) and four adults. No changes were made based on feedback and the survey took less than 10 minutes.

Each of the six predictor variables in the study consisted of three items serving as observed variables of the underlying construct while TKD commitment included four items. The selected items for this study, and previous studies before, have been consistent and modifications have only been made to adjust for the activity under study (e.g., playing tennis versus playing soccer). Previous research has found that the constructs are internally reliable (e.g., Cronbach alpha $>.70)$ and valid (e.g., standardized factor loadings $>.50$ ) (Hair, Black, Babin, Anderson, \& Tatham, 2006). The model has also been shown to be valid in a variety of sport contexts such as adult fitness participation (Alexandris et al., 2002), adult tennis (Casper et al., 2007) and windsurfer participants, (Jeon \& Ridinger, 2009), and in multiple youth sports (Scanlan, Carpenter, Schmidt, et al., 1993; Weiss et al., 2001). Item responses were based on a 5-point Likert-type scale that differed depending on the question (e.g., "none/not at all" to "very much/a lot") for this study.

\section{Data Analysis}

The first step was a descriptive analysis and an examination of the data for normality (i.e., Skewness and Kurtosis). With 95\% confidence interval the critical value $(<+/-2.0)$ for skewness and $(<+/-3.0)$ for kurtosis were applied (George \& Mallerey, 2010; Tabachnick \& Fiddell, 2001).

The second step was to conduct a Confirmatory Factor Analysis (CFA) through a measurement model to examine each latent construct (e.g., commitment, enjoyment, involvement alternatives, involvement opportunities, personal investments, social constraints, and social support) based on factor structure, measurement model fit statistics, construct reliability (CR) and average variance extracted (AVE). Due to the purpose of this study examining adults and youth, measurement invariance testing between the groups CFA model was conducted. The last step consisted of conducting a multiplegroup (youth and adult) path analysis of 
structural model to examine conceptual connections between latent variables. While testing the models, the following fit indices were used: Comparative Fit Index (CFI), Tucker-Lewis Fit Index (TLI), and Root Mean Square Error of Approximation (RMSEA). According to $\mathrm{Hu}$ and Bentler (1999), fit index values of CFI and TLI above .90 and RMSEA values less than .05 are considered acceptable. Expanded details for each step are provided in the following section.

\section{Results}

Skewness and kurtosis values of the items, except three, were in an appropriate range. The three items (related to enjoyment) were found to be slightly negative from -2.2 to -2.5 for skewness and from 5.3 to 7.5 for kurtosis. However, these three items were retained as there was variability, the values were not very high, and sample size has an effect on the slightly high values of skewness and kurtosis (SPC for Excel, 2016)

CFA assessed reliability and validity of the constructs based on factor structure, measurement model fit statistics, composite reliability (CR), and average variance extracted (AVE) (Garson, 2013; Hu \& Bentler, 1999). CFA analysis revealed that the standardized factor loadings of two items of involvement alternatives and one involvement opportunity were below .50 . After removing these three items CFA analysis was conducted and presented acceptable model fit $[(\chi 2=467.75(d f=$
168), $\mathrm{CFI}=.94, \mathrm{NFI}=.91, \mathrm{TLI}=.92$, RMSEA = .06)]. All standardized factor loadings of 21 items were acceptable (from .56 to .89$)$ and the values of reliability coefficients and average variance extracted indicted that the constructs were reliable and valid (Hu \& Bentler, 1999). Table 2 presents standardized factor loadings of 21 items, and composite reliabilities (CR) and average variance explained (AVE) of seven variables.

Measurement invariance test was conducted to ensure measurement model validity for both youth and adults. The chisquare difference test rejected the null hypothesis that two groups are not significantly different, $\chi 2(22)=110.7, p<$ .01. However, the chi-square test is sensitive to sample size such as rejecting a reasonable model due to the large sample size (Meade, 2005). Thus, other types of goodness of model fit were evaluated. The results presented an acceptable model fit $\left(\chi^{2}=\right.$ $705.685(d f=336), \chi 2 / d f=2.100$, RMSEA $=.051, \mathrm{CFI}=.926, \mathrm{TLI}=.907, \mathrm{PCFI}=$ $.741)$. This indicates that the items underling the construct have similar meaning for youth and adult participants.

The results of a multiple-group path and indirect mediation analyses are reported in Table 3 and 4. For the adults, among the six predictor variables, enjoyment, personal investment, and involvement opportunities were significant positive predictors of TKD commitment. However, involvement alternatives were a negative predictor of enjoyment and TKD commitment. Social 
constraints were a negative predictor of enjoyment only.

For the youth sample, the results indicated that enjoyment, involvement opportunities, personal investment, and social support were significant positive predictors of TKD commitment while involvement alternatives were negative predictors of enjoyment.

\section{Discussion}

This study examined the SCM with adult and youth TKD participants by examining the six predictor variables for their TKD commitment. This was the first study to test the SCM with adult and youth participating in an identical sport. Thus, the findings of this study add to SCM theory and may provide valuable information to inform marketing strategies for both age segments. The discussion section will highlight similarities and differences as well as practical implications.

\section{Theoretical Implications}

As this is the first study to use a crosssectional design capturing adults and youth, there are several theoretical implications. First this study provides evidence that there are commonalities within the SCM that may be core predictors of commitment, and indirectly enjoyment, to the activity no matter developmental age. The finding of commonalties lends to practical marketing implications where marketing or communication efforts can be suited to target all age levels. Inversely, differences help identify a unique way to communicate and market based on age level that add unique points of difference and add value to participating in the activity. While past research has shown similarities and differences in SCM predictors between two age groups (e.g., college and adults tennis players; Casper \& Andrew, 2008), it was unknown whether the findings were due to the sample and setting differences. Therefore, this study provided evidence that testing the SCM based on age within the same activity is warranted.

The findings of this study show that the SCM is a valid measure to use when comparing age differences. As part of the results, invariance testing found that adults and youth interpret the items of the SCM similar. While the level of importance for each item may differ, the underlying meanings and interpretation of the measures does not. Further, our study along with other more recent studies (Crocker \& Augaitis, 2010) shows that there are clear common predictors (enjoyment and involvement opportunities) that explain a large majority of the variance of commitment. Additionally, since we looked at indirect effect with enjoyment as a mediator, variables that were not significant in predicting commitment can help in understanding participant's enjoyment of the activity. The results confirm the findings of Casper et al. (2007), and Weiss et al. (2001). 


\section{Similarities}

Among the six predictor variables involvement opportunities, personal investments, and enjoyment were significant predictors of TKD commitment.

Involvement opportunities. A main factor related to TKD commitment is the unique (sport specific) opportunities that participation affords. This finding is consistent with previous SCM studies. For example, the results of studies examining tennis participants (Casper et al., 2007) and windsurfers (Jeon \& Ridinger, 2009) indicated that involvement opportunities were the strongest predictor of commitment of adult participants. Even though many previous SCM studies with youth showed enjoyment was the strongest predictor of commitment, involvement opportunities were often the second strongest predictor of commitment (Scanlan, Simons, Carpenter, et al., 1993; Weiss et al., 2001). The involvement opportunities associated with TKD may be a key reason for TKD's popularity worldwide. It is one of the few activities where participants are encouraged to kick, scream and even break objects. Recognizing this, TKD practitioners have developed training methods to increase selfconfidence and emotional release (e.g., breaking boards, practicing TKD demonstration, and exercising TKD formation) while still holding the original elements of ancient martial arts (e.g., selfdefense skills). These opportunities are only realized during participation and therefore the strong relationship with commitment exists.

Enjoyment. Consistent with past theory and research, it is not surprising that enjoyment was one of the largest significant predictors of commitment for both youth and adults. The TKD participants that have fun and enjoy the activity are committed. This study adds more evidence to the importance of enjoyment in a variety of sport settings and among all age groups.

Personal investments. While not as strong as involvement opportunities and enjoyment, personal investments were a significant variable of TKD commitment for both adults and youth and this finding is consistent with previous SCM research (Alexandris et al., 2002; Casper et al., 2007; Scanlan, Simons, Carpenter, et al., 1993). Personal investments included monetary and non-monetary (e.g., time) elements. Compared with other recreational sports, participation in TKD requires a significant financial investment such as monthly fees, equipment purchase, testing fees, etc. TKD has a well-organized belt system and requires students to participate for a certain period and take a test to move up the next level. Moreover, it takes at least three years to achieve Black-Belt status. If the goal is to achieve a Black-Belt, each TKD participant must invest resources that are lost if the participant withdraws. In fact, the investment model (Rusbult, 1988), that is a foundation theory for the SCM, stated that more contribution (e.g., time and energy) should build higher commitment. Thus this 
study demonstrates Rusbult's (1988)

assertion in both age categories.

\section{Differences}

The results for predicting commitment found involvement alternatives as a significant predictor of TKD commitment for adults only, while social support was a significant predictor of TKD commitment for youth only.

Involvement alternatives. Within the SCM, involvement alternatives are the detractor of commitment. This study showed that involvement alternatives were a significant detractor of TKD commitment for adults, but not for youth. This is a key finding since social support was important for youth and not for adults. Adult continued involvement in TKD may depend on their perception of other viable alternatives. To retain adult participants, TKD must be viewed as better than other activities and the unique aspects of the sport must be viewed as superior to other participation options. This finding has multiple implications for TKD studios where they must compete with other leisure-time activities for the adult participation market.

Social support. Past SCM research examining youth found social support to be a weak or non-significant influence on commitment (Casper et al, 2007; Weiss et al., 2001). This study found social support to be significant for youth. It may be interpreted that the significant role of social support is based on the sport itself. TKD's educational philosophy teaches the importance of friendships and collaboration (e.g., youth TKD demo team providing mass formation show). Classes/lessons are primarily in groups and relationships develop over time. Thus, the youth, in this study, perceived the existing social relationships were important and therefore increased their commitment to the sport. Social support reflects feelings of encouragement and support that a sport participant receives from significant others (i.e., family and friends). According to Lantz (2002), parents serve as the primary reasons for youth involvement and their support is important for continued participation. Social support was rated to be important to the adults respondents $(M=3.69)$, but the variable did not statistically significant predict for TKD commitment, so while participants may view that their participation is viewed positively by significant others, it is not related to commitment to the sport. For adults, participation may be more for purposes such as exercise/fitness and selfdefense/fighting and continued participation is not dependent on others.

\section{Indirect impact (enjoyment as a mediator)}

For both age groups, involvement opportunities and personal investments had a positive influence on enjoyment while involvement alternatives were a significant negative predictor of enjoyment. Similarly to predicting commitment, involvement 
opportunities were a primary predictor of enjoyment for both adults and youth. The influence of personal investments and involvement alternatives was stronger for adults. For involvement alternatives, adults might have more participation options than youth and these, of course, detract from TKD enjoyment. This finding corresponds with past SCM studies with adults that examined the influence of predictor variables on enjoyment (Casper et al., 2007). For personal investments, youth may devote the same amount of time and effort as adults. However, this study indicated pecuniary investments such as monthly fees and testing fees had a lower influence for youth than for adults. This finding may result from parents being the primary monetary resource for youth participants. The findings indicated that social support and social constraints did not predict enjoyment for youth and social constraints were a weak detractor of enjoyment for adults. This finding is interesting as it shows that the social influences that keep one committed did not necessarily make the TKD participation more fun. Youth in this study may continue to participate in TKD because of significant others; however, other variables (e.g., involvement opportunities) are more important and provide unique fun experiences (e.g., hitting and kicking) and heuristic outcomes.

\section{Implications}

This study highlights that within the same activity, two age segments are committed to the sport for similar and dissimilar reasons. First related to the similarities, retention efforts can be generalized if they relate to the commonalties of the findings. For example, involvement opportunities were strong predictor variables for adults and youth. Thus, TKD programs that emphasize distinct experiences that can be obtained only through TKD (e.g., hitting, kicking, breaking boards, screaming, etc.) can encourage adult and youth participants' retention. Another similarity was that personal investments had an important influence on commitment. Continuing investments (e.g., time and money) may be driven by strong goals for TKD participants. In fact, since TKD holds both characteristics as modernized sport activity and ancient martial arts, participants have diverse goals such as competition, fitness, self-defense, fun, etc. (Kim \& Zhang, 2015). As these may be the primary elements that lead to continuing personal investments, managers and instructors might need to clearly understand participants' personal goals and try to apply different teaching methods based on those goals. Implications related to enjoyment suggest keeping the sport fun. Thus, programming that emphasizes fun activities should be implemented such as weapons training (e.g., a wooden sword and a stick weapon) and action movie stunts help with enjoyment of the sport.

The differences between adults and youth suggest age dependent retention 
efforts, as well. First, since social support was significant for youth, strategies related to developing social bonds (e.g., birthday party, demo team, etc.) and incentivizing students to recruit friends to join a studio may be effective tactics.

\section{Limitations and future research}

One major limitation is that while we were comparing age groups, the age range for each category was very broad (under and over 18 years old). It is well documented, and recognized by the authors, that the psychological determinants with each category can be very different (e.g., adolescent versus teenager). The same may apply for a young adult versus older adult. While further segmentation of age is warranted, these age categories were used based on the programming offered in TKD. While our study examined active participants, future research with nonparticipants is warranted, especially related to recruitment of new TKD participants. Also, even though we surveyed four TKD studios, all four were located in the same region of the U.S. and all had similar programming and martial arts methods. Thus, subjects in this study may have similar perceptions regarding TKD instruction and programming. Additionally, we used a selfreport survey and had many young respondents whose parents were responsible for survey interpretation. Therefore, more caution might be used when interpreting the findings of youth participants.
Future research may continue this line of research with other sports or leisure activities. For example soccer, in the form of leagues, is a popular adult recreational sport and it would be interesting to see if our results are replicated in other sports with a wide age range. Future research should look at further segmentation. For example, Casper and Babkes-Stellino (2008) found differences in predictors of commitment with participants playing the same sport based on demographic variables. The SCM in this study included six predictor variables of commitment. However, it could be possible there are other variables that might be important for commitment such as participants' skill level and ability (perceived competence). Finally, the SCM focuses on participants continued involvement. Therefore, a longitudinal study with the SCM might provide better understanding for sport participants. Examining the participants' reasons for continued participation or withdrawal may provide researchers and practitioners a better understanding about what other variables influence sport participation and retention.

\section{Conclusion}

Past research with the SCM has found that the predictors of commitment may be both activity and socio-demographic dependent. This study examined TKD to establish how the SCM differs or is similar based on two age categories. Specifically we found that enjoyment, involvement 
opportunities and personal investments were important for commitment in adult and youth participants while other predictor variables differed between the age segments. In summary, this study contributed to the growing research on sport commitment and demonstrated that the reasons for continued participation are unique based on developmental age. Additionally, specific similarities and differences inform decisions related to practical implications focusing on retention of participants to TKD providers. 


\section{References}

Allison, P. D. (2001). Missing data.

Quantitative applications in the social sciences (1st ed.). Sage: Thousand Oaks, CA.

Alexandris, K., Zahariadis, P., Tsorbatzoudis, C., \& Grouios, G. (2002). Testing the sport commitment model in the contest of exercise and fitness participation. Journal of Sport Behavior, 25(3), 217 230.

Bodet, G. (2012). Loyalty in sport participation services: An examination of the mediating role of psychological commitment. Journal of Sport Management, 26(1), 30-42.

Byeon, J., Kwon, Y., \& Park, S. (2008). Effects of 12 week taekwondo program on physical fitness, body composition, and physical selfefficacy in middle aged women. Korean Journal of Sport Science, 19(2), 12-20.

Casper, J. M., \& Andrew, D. A. (2008). Sport commitment differences among tennis players on the basis of participation outlet and skill level. Journal of Sport Behavior, 31(3), 201219.

Casper, J. M., Gray, D. P., \& BabkesStellino, M. L. (2007). A sport commitment model perspective on adult tennis players' participation frequency and purchase intention. Sport Management Review, 10(3), 253278.
Casper, J. M. \& Babkes-Stellino, M. L. (2008). Demographic predictors of recreational tennis participant's sport commitment. Journal of Park and Recreation Administration, 26(3), 93115.

Carpenter, P. J., \& Coleman, R. (1998). A longitudinal study of elite youth cricketers' commitment. International Journal of Sport Psychology, 29, 195-210.

Crocker, P. R. \& Augaitis, L. (2010). Commitment in age class adult triathletes: examining gender differences in the Sport Commitment Model. International Journal of Sport Psychology, 41, 177-194

Fernandes, N. E., Correia, A. H., Abreu, A. M., \& Biscaia, R. (2013). Relationship between sport commitment and sport consumer behavior. / Relações entreo compromisso desportivo e o comportamento de consumo de desporto. Motricidade, 9(4), 2-11.

Fong, S. S., \& Ng, G. Y. (2011). Does taekwondo training improve physical fitness. Physical Therapy in Sport, 12(2), 100-106.

Garson, G. D. (2013). Factor analysis. Asheboro, NC: Statistical Associates Publishers.

George, D., \& Mallery, P. (2011). SPSS for Windows step by step: a simple guide and reference 18.0 update. (11th ed.). Boston, MA: Pearson/Allyn \& Bacon.

Hair, J. F., Black, W. C., Babin, B. J., Anderson, R. E., \& Tatham, R. L. 
(2006). Multivariate Data Analysis. (6th ed.) Upper Saddle River, NJ: Pearson Prentice Hall.

Hu, L. \& Bentler, P. M. (1999). Cutoff criteria for fit indexes in covariance structure analysis: Conventional criteria versus new alternatives. Structural Equation Modeling: A Multidisciplinary Journal, 6(1), 1-55.

Jeon, J., \& Ridinger, L. L. (2009). An examination of sport commitment of windsurfers. Journal of Sport Behavior, 32(3), 325-338.

Kang, S. (2004). The study on existing situation and development plan of taekwondo. The Journal of Korean Alliance of Martial Arts, 6(2), 165-180.

Kelley, H. H. (1983). Love and commitment. In H.H. Kelley, E. Berscheid, A. Christensen, J.H. Harvey, T.L. Huston, G. Levinger, E. McClintock, L.A. Peplau, \& D.R. Peterson (Eds.), Close relationships (pp. 265-314). New York, NY: W.H. Freeman and Company.

Kelley, H. H. \& Thibaut, J. W. (1978)

Interpersonal relations: $A$ theory of interdependence. New York, NY: WileyInterscience.

Kim, J., Dattilo, J., \& Heo, J. (2011).

Taekwondo participation as serious leisure for life satisfaction and health. Journal of Leisure Research, 43(4), 545559.

Kim, J. W., James, J. D., \& Kim, Y. K. (2013). A model of the relationship among sport consumer motives, spectator commitment, and behavioral intentions. Sport Management Review, 16(2), 173-185.

Kim, M. K., \& Zhang, J. J. (2015).

Promoting an asian sport to the world: the case of Taekwondo. In H. K. Leng \& N. Y. Hsu (Eds.), Emerging trends and innovation in sports marketing and management in Asia (pp. 192-204). Hershey, PA: IGI Global.

Kim, M. K., Zhang, J. J., \& Ko, Y. J. (2009). Dimensions of market demand associated with taekwondo schools in North America: development of a scale. Sport Management Review, 12(3), 149-166.

Ko, K., Seok, B., \& Kwon, S. (2013). A study on the necessity of sport for all programs between adults' participation motivation and the intention of exercise adherence to Taekwondo. The Korea Journal of Sports Science, 22(2), 603-615.

Lakes, K.D. (2013). The value of youth education in taekwondo training: Scientific evidence for the benefits of training children. The Taekwondo Journal of Kukkiwon, 4(3), 45-63.

Lakes, K.D., Bryars, T., Emmerson, N., Sirisinihal, S., Salim, N., Arastoo, S., Kang, D., Shim, L., Wong, D., \& Kang, C. J. (2013). The healthy for life taekwondo pilot study: a preliminary evaluation of effects on executive function and BMI, feasibility, and acceptability. Mental Health and Physical Activity, 6, 181-188. 
Lantz, J. (2002). Family development and the martial arts: A phenomenological study. Contemporary Family Therapy, 24(4), 565.

Meade, A. W. (2005). Sample size and tests of measurement invariance. Paper presented at the 20th annual conference of the Society for Industrial and Organizational Psychology, Los Angeles, CA. Retrieved April 20, 2016, from https://pdfs.semanticscholar.org/05 13/2416492dd8d9d0c4f0916e040d88 24e13277.pdf

Penedo, F. J., \& Dahn, J. R. (2005). Exercise and well-being: A review of mental and physical health benefits associated with physical activity. Current Opinion in Psychiatry, 18(2), 189-193.

Rusbult, C. E. (1988). Commitment in close relationships: The investment model. In L.A. Peplau, D.O. Sears, S.E. Taylor, \& J.L. Freedman (Eds.), Readings in social psychology: Classic and contemporary contributions (pp. 147-157). Englewood Cliffs, NJ: Prentice Hall. Scanlan, T. K., Carpenter, P. J., Schmidt, G.W., Simons, J. R., \& Keeler, B. (1993). An introduction to the sport commitment model. Journal of Sport \& Exercise Psychology, 15, 1-15.

Scanlan, T. K., Ravizza, K., \& Stein, G. L. (1989). An in-depth study of former elite figure skaters: II. Sources of enjoyment. Journal of Sport \& Exercise Psychology, 11, 65-83.
Scanlan, T. K., Russell, D. G., Beals, K. P., \& Scanlan, L. A. (2003). Project on elite athlete commitment (PEAK): II. A direct test and expansion of the sport commitment model with elite amateur sportsmen. Journal of Sport \& Exercise Psychology, 25(3), 377-401.

Scanlan, T. K., Russell, D. G., Wilson, N.C., \& Scanlan, L. A. (2003). Project on elite athlete commitment (PEAK): I. Introduction and methodology, Journal of Sport \& Exercise Psychology, 25(3), 360-376.

Scanlan, T. K., \& Simons, J. P. (1992). The construct of sport enjoyment. In G.C. Roberts (Ed.), Motivation in sport and exercise (pp. 199-215). Champaign, IL: Human Kinetics.

Scanlan, T. K., Simons, J.P., Carpenter, P. J., Schmidt, G. W., \& Keeler, B. (1993). The sport commitment model: Measurement development for the youth-sport domain. Journal of Sport \& Exercise psychology, 15, 16-38.

SPC for Excel. (2015). Are the skewness and kurtosis useful statistics? Retrieved April 20, 2016, from https://www.spcforexcel.com/knowl edge/basic-statistics/are-skewnessand-kurtosis-usefulstatistics\#skewness

Sport Business Research Network. (2014). Martial arts participation. Retrieved November 10, 2014, from http://www.sbrnet.com/mainsports /martialarts.asp 
Stein, G. L., \& Scanlan, T. K. (1992). Goal attainment and non-goal occurrences as underlying mechanisms to an athlete's sources of enjoyment. Pediatric Exercise Science, 4(2), 150-165.

Tabachnick, B. G., \& Fidell, L. S. (2001). Using multivariate statistics. (4th ed.). Needham Heights, MA: A Pearson Education Company.

Weiss, M. R., Kimmel, L. A., \& Smith, A. L. (2001). Determinants of sport commitment among junior tennis players: Enjoyment as a mediating variable. Pediatric Exercise Science, 13, 131-144.

World Taekwondo Federation (2014). About WEF-organizaiton. Retrieved November 20, 2014, from http://www.wtf.org/

Young, B. W., \& Medic, N. (2011).

Examining social influences on the sport commitment of masters swimmers. Psychology of Sport and Exercise, 12, 168-175.

Zeng, H. Z., Cynarski, W. J., Baatz, S., \& Park, S. J. (2015). Exploring motivations of taekwondo athletes/students in New York City. World Journal of Education, 5(5), 51-63. 


\section{Tables}

Table 1

Descriptive statistics of the sample

\begin{tabular}{|c|c|c|c|c|}
\hline \multirow[b]{2}{*}{ Variables } & \multicolumn{2}{|c|}{ Adult } & \multicolumn{2}{|c|}{ Youth } \\
\hline & $N$ & $M$ & $N$ & $M$ \\
\hline Age & 205 & 38.1 & 227 & 10.9 \\
\hline \multirow[t]{2}{*}{ Visit Time (per week) } & & 3.07 & & 3.17 \\
\hline & \multicolumn{2}{|c|}{ Adult } & \multicolumn{2}{|c|}{ Youth } \\
\hline Variables & $N$ & $\%$ & $N$ & $\%$ \\
\hline \multicolumn{5}{|l|}{ Years of Participation } \\
\hline Under 1 year & 59 & 29.5 & 86 & 38.6 \\
\hline $1-2$ years & 56 & 28.0 & 39 & 17.5 \\
\hline $3-4$ years & 39 & 19.5 & 55 & 24.7 \\
\hline 5 years or more & 46 & 23.0 & 43 & 19.3 \\
\hline \multicolumn{5}{|l|}{ Gender } \\
\hline Male & 109 & 52.9 & 154 & 67.8 \\
\hline Female & 96 & 47.1 & 73 & 32.2 \\
\hline \multicolumn{5}{|l|}{ Race } \\
\hline Caucasian & 148 & 72.2 & 124 & 55.6 \\
\hline African American & 18 & 8.8 & 22 & 9.9 \\
\hline Asian & 23 & 11.2 & 41 & 18.4 \\
\hline $\begin{array}{l}\text { Native Hawaiian / } \\
\text { Pacific Islander }\end{array}$ & 0 & 0 & 3 & 1.3 \\
\hline Hispanic / Latino & 7 & 3.4 & 13 & 5.8 \\
\hline Multi-ethnic / Mixed race & 7 & 2.4 & 16 & 7.2 \\
\hline Other & 2 & 1 & 4 & 1.8 \\
\hline \multicolumn{5}{|l|}{ Income (only adult) } \\
\hline under $\$ 24,000$ & 18 & 9.3 & & \\
\hline$\$ 24,001-\$ 40,000$ & 19 & 9.8 & & \\
\hline$\$ 40,001-\$ 65,000$ & 29 & 15.0 & & \\
\hline$\$ 65,001-\$ 95,000$ & 41 & 21.2 & & \\
\hline$\$ 95,001-\$ 120,000$ & 28 & 14.5 & & \\
\hline$\$ 120,001$ or more & 58 & 30.1 & & \\
\hline
\end{tabular}


Table 2

Factor loadings, Reliability coefficients, and Average variance extracted

\begin{tabular}{|c|c|c|c|c|c|}
\hline Factors & Items & & $\lambda$ & $\alpha$ & AVE \\
\hline \multirow{4}{*}{$\begin{array}{l}\text { TKD } \\
\text { Commitment }\end{array}$} & $\mathrm{COM} 1$ & I am determined to get to the next belt level. & .622 & \multirow{4}{*}{.807} & \multirow{4}{*}{.514} \\
\hline & COM2 & How determined are you to continue & .850 & & \\
\hline & COM3 & $\begin{array}{l}\text { How hard would it be for you to quit } \\
\text { Taekwondo? }\end{array}$ & .728 & & \\
\hline & COM4 & $\begin{array}{l}\text { How proud are you to tell other that you do } \\
\text { Taekwondo? }\end{array}$ & .646 & & \\
\hline \multirow{3}{*}{$\begin{array}{l}\text { TKD } \\
\text { Enjoyment }\end{array}$} & ENJ1 & I enjoy participating in Taekwondo. & .881 & \multirow{3}{*}{.878} & \multirow{3}{*}{.706} \\
\hline & ENJ2 & I like Taekwondo. & .770 & & \\
\hline & ENJ3 & I have fun participating in Taekwondo. & .866 & & \\
\hline \multirow{2}{*}{$\begin{array}{l}\text { Involvement } \\
\text { Alternatives }\end{array}$} & IA3 & $\begin{array}{l}\text { Are you thinking of doing this activity instead } \\
\text { of Taekwondo? }\end{array}$ & .866 & \multirow{2}{*}{.708} & \multirow{2}{*}{.556} \\
\hline & IA4 & $\begin{array}{l}\text { Is it difficult to choose Taekwondo over your } \\
\text { chosen alternate activity? }\end{array}$ & .602 & & \\
\hline \multirow{3}{*}{$\begin{array}{l}\text { Involvement } \\
\text { Opportunities }\end{array}$} & $\mathrm{IO} 1$ & $\begin{array}{l}\text { I would miss being considered a Taekwondo } \\
\text { athlete if I quit. }\end{array}$ & .733 & \multirow{3}{*}{.779} & \multirow{3}{*}{.548} \\
\hline & $\mathrm{IO} 2$ & $\begin{array}{l}\text { I would miss the unique experience of } \\
\text { Taekwondo if I quit. }\end{array}$ & .881 & & \\
\hline & $\mathrm{IO} 4$ & $\begin{array}{l}\text { I would miss the people that I have met if I } \\
\text { quit Taekwondo. }\end{array}$ & .575 & & \\
\hline \multirow{3}{*}{$\begin{array}{l}\text { Personal } \\
\text { Investments }\end{array}$} & PI1 & $\begin{array}{l}\text { How much energy do you put into } \\
\text { Taekwondo? }\end{array}$ & .817 & \multirow{3}{*}{.868} & \multirow{3}{*}{.687} \\
\hline & PI2 & How much time do you put into Taekwondo? & .774 & & \\
\hline & PI3 & $\begin{array}{l}\text { How much effort do you put into } \\
\text { Taekwondo? }\end{array}$ & .892 & & \\
\hline \multirow{3}{*}{$\begin{array}{l}\text { Social } \\
\text { Constraints }\end{array}$} & SC1 & $\begin{array}{l}\text { I feel that I have to participate in Taekwondo } \\
\text { to be with my friends. }\end{array}$ & .572 & \multirow{3}{*}{.701} & \multirow{3}{*}{.441} \\
\hline & SC2 & $\begin{array}{l}\text { I feel that I participate in Taekwondo so } \\
\text { others do not feel that I am a quitter. }\end{array}$ & .704 & & \\
\hline & SC3 & $\begin{array}{l}\text { I feel that I do Taekwondo more for other } \\
\text { than for myself. }\end{array}$ & .707 & & \\
\hline \multirow{3}{*}{$\begin{array}{l}\text { Social } \\
\text { Support }\end{array}$} & SS1 & $\begin{array}{l}\text { People say things that make me feel good } \\
\text { about participating in Taekwondo. }\end{array}$ & .560 & \multirow{3}{*}{.725} & \multirow{3}{*}{.472} \\
\hline & SS2 & $\begin{array}{l}\text { Significant others encourage me to do } \\
\text { Taekwondo. }\end{array}$ & .702 & & \\
\hline & SS3 & $\begin{array}{l}\text { I feel I receive support from significant } \\
\text { others to do Taekwondo. }\end{array}$ & .780 & & \\
\hline
\end{tabular}


Table 3

Adult Standard Normali (NT) and Bootstrap Methods

\begin{tabular}{|c|c|c|c|c|c|c|}
\hline \multirow{3}{*}{ Path } & \multicolumn{2}{|c|}{ Estimate } & \multicolumn{4}{|c|}{$95 \%$ Confidence Interval } \\
\hline & $\beta$ & $S E$ & \multicolumn{2}{|c|}{ Bootstrap Percentile } & \multicolumn{2}{|c|}{$\begin{array}{l}\text { Bootstrap with bias } \\
\text { Corrections }\end{array}$} \\
\hline & $-.098^{* *}$ & .019 & -.145 & -.051 & -.151 & -.054 \\
\hline $\mathrm{TE} \rightarrow \mathrm{TC}$ & $.341 * *$ & .081 & .169 & .506 & .168 & .505 \\
\hline $\mathrm{IA} \rightarrow \mathrm{TC}$ & $-.048^{*}$ & .024 & -.097 & .001 & -.095 & .003 \\
\hline $\mathrm{IA} \rightarrow \mathrm{TE} \rightarrow \mathrm{TC}$ & $-.033 * *$ & .010 & -.061 & -.013 & -.066 & -.015 \\
\hline $\mathrm{IO} \rightarrow \mathrm{TE}$ & $.290 * *$ & .027 & .196 & .386 & .196 & .386 \\
\hline $\mathrm{TE} \rightarrow \mathrm{TC}$ & $.341 * *$ & .081 & .169 & .506 & .168 & .505 \\
\hline $\mathrm{IO} \rightarrow \mathrm{TC}$ & $.400 * *$ & .039 & .264 & .562 & .275 & .577 \\
\hline $\mathrm{IO} \rightarrow \mathrm{TE} \rightarrow \mathrm{TC}$ & $.099 * *$ & .835 & .042 & .166 & .044 & .170 \\
\hline $\mathrm{PI} \rightarrow \mathrm{TE}$ & $.253 * *$ & .028 & .161 & .341 & .170 & .350 \\
\hline $\mathrm{PI} \rightarrow \mathrm{TC}$ & $.185^{* *}$ & .038 & .081 & .282 & .085 & .289 \\
\hline $\mathrm{PI} \rightarrow \mathrm{TE} \rightarrow \mathrm{TC}$ & $.086 * *$ & .023 & .037 & .138 & .044 & .144 \\
\hline $\mathrm{SC} \rightarrow \mathrm{TE}$ & $-.038^{*}$ & .019 & -.075 & -.003 & -.074 & -.002 \\
\hline $\mathrm{SC} \rightarrow \mathrm{TC}$ & -.001 & .022 & -.042 & .039 & -.042 & .040 \\
\hline $\mathrm{SC} \rightarrow \mathrm{TE} \rightarrow \mathrm{TC}$ & $-.013^{*}$ & .007 & -.027 & -.001 & -.028 & -.002 \\
\hline $\mathrm{SS} \rightarrow \mathrm{TE}$ & .020 & .020 & -.019 & .062 & -.018 & .064 \\
\hline $\mathrm{SS} \rightarrow \mathrm{TC}$ & .032 & .023 & -.025 & .091 & -.028 & .087 \\
\hline $\mathrm{SS} \rightarrow \mathrm{TE} \rightarrow \mathrm{TC}$ & .007 & .007 & -.007 & .023 & -.005 & .027 \\
\hline
\end{tabular}

Note. $N=205 . \mathrm{NT}=\mathrm{Baron}-\mathrm{Kenny}$-Sobel method. Estimates are unstandardized. IA = Involvement Alternatives; IO = Involvement Opportunities; PI = Personal Investments; SC = Social Constraints; SS = Social Support; TE = Taekwondo Enjoyment; $\mathrm{TC}=$ Taekwondo Commitment. $* p<.05 . * * p<.01$. 
Table 4

Youth Standard Normali (NT) and Bootstrap Methods

\begin{tabular}{|c|c|c|c|c|c|c|}
\hline \multirow{3}{*}{$\begin{array}{c}\text { Path } \\
\mathrm{IA} \rightarrow \mathrm{TE}\end{array}$} & \multicolumn{2}{|c|}{ Estimate } & \multicolumn{4}{|c|}{$95 \%$ Confidence Interval } \\
\hline & $\beta$ & $S E$ & \multicolumn{2}{|c|}{ Bootstrap Percentile } & \multicolumn{2}{|c|}{$\begin{array}{l}\text { Bootstrap with bias } \\
\text { Corrections }\end{array}$} \\
\hline & $-.071 * *$ & .025 & -.122 & -.019 & -.123 & -.022 \\
\hline $\mathrm{TE} \rightarrow \mathrm{TC}$ & $.457 * *$ & .056 & .305 & .600 & .323 & .618 \\
\hline $\mathrm{IA} \rightarrow \mathrm{TC}$ & -.024 & .021 & -.066 & .019 & -.065 & .019 \\
\hline $\mathrm{IA} \rightarrow \mathrm{TE} \rightarrow \mathrm{TC}$ & $-.032 * *$ & .012 & -.058 & -.008 & -.063 & -.012 \\
\hline $\mathrm{IO} \rightarrow \mathrm{TE}$ & $.490 * *$ & .036 & .346 & .621 & .353 & .625 \\
\hline $\mathrm{TE} \rightarrow \mathrm{TC}$ & $.457 * *$ & .056 & .305 & .600 & .323 & .618 \\
\hline $\mathrm{IO} \rightarrow \mathrm{TC}$ & $.387 * *$ & .040 & .269 & .503 & .278 & .514 \\
\hline $\mathrm{IO} \rightarrow \mathrm{TE} \rightarrow \mathrm{TC}$ & $.224 * *$ & .032 & .131 & .322 & .139 & .340 \\
\hline $\mathrm{PI} \rightarrow \mathrm{TE}$ & $.259 * *$ & .038 & .140 & .378 & .135 & .375 \\
\hline $\mathrm{PI} \rightarrow \mathrm{TC}$ & $.096^{*}$ & .035 & -.005 & .211 & -.013 & .201 \\
\hline $\mathrm{PI} \rightarrow \mathrm{TE} \rightarrow \mathrm{TC}$ & $.008^{* *}$ & .023 & .055 & .191 & .062 & .199 \\
\hline $\mathrm{SC} \rightarrow \mathrm{TE}$ & -.041 & .025 & -.093 & .006 & -.092 & .008 \\
\hline $\mathrm{SC} \rightarrow \mathrm{TC}$ & .026 & .021 & -.010 & .058 & -.007 & .062 \\
\hline $\mathrm{SC} \rightarrow \mathrm{TE} \rightarrow \mathrm{TC}$ & $-.019 *$ & .012 & -.043 & .002 & -.044 & .002 \\
\hline $\mathrm{SS} \rightarrow \mathrm{TE}$ & .036 & .031 & -.039 & .118 & -.041 & .116 \\
\hline $\mathrm{SS} \rightarrow \mathrm{TC}$ & $.096^{* *}$ & .026 & .036 & .163 & .031 & .159 \\
\hline $\mathrm{SS} \rightarrow \mathrm{TE} \rightarrow \mathrm{TC}$ & .016 & .014 & -.019 & .052 & -.018 & .052 \\
\hline
\end{tabular}

Note. $N=205$. NT = Baron-Kenny-Sobel method. Estimates are unstandardized. IA = Involvement Alternatives; IO = Involvement Opportunities; PI = Personal Investments; SC = Social Constraints; SS = Social Support; TE = Taekwondo Enjoyment; $\mathrm{TC}=$ Taekwondo Commitment.

$* p<.05 . * * p<.01$. 
Figure 1

Adult Direct and Indirect Path Analysis

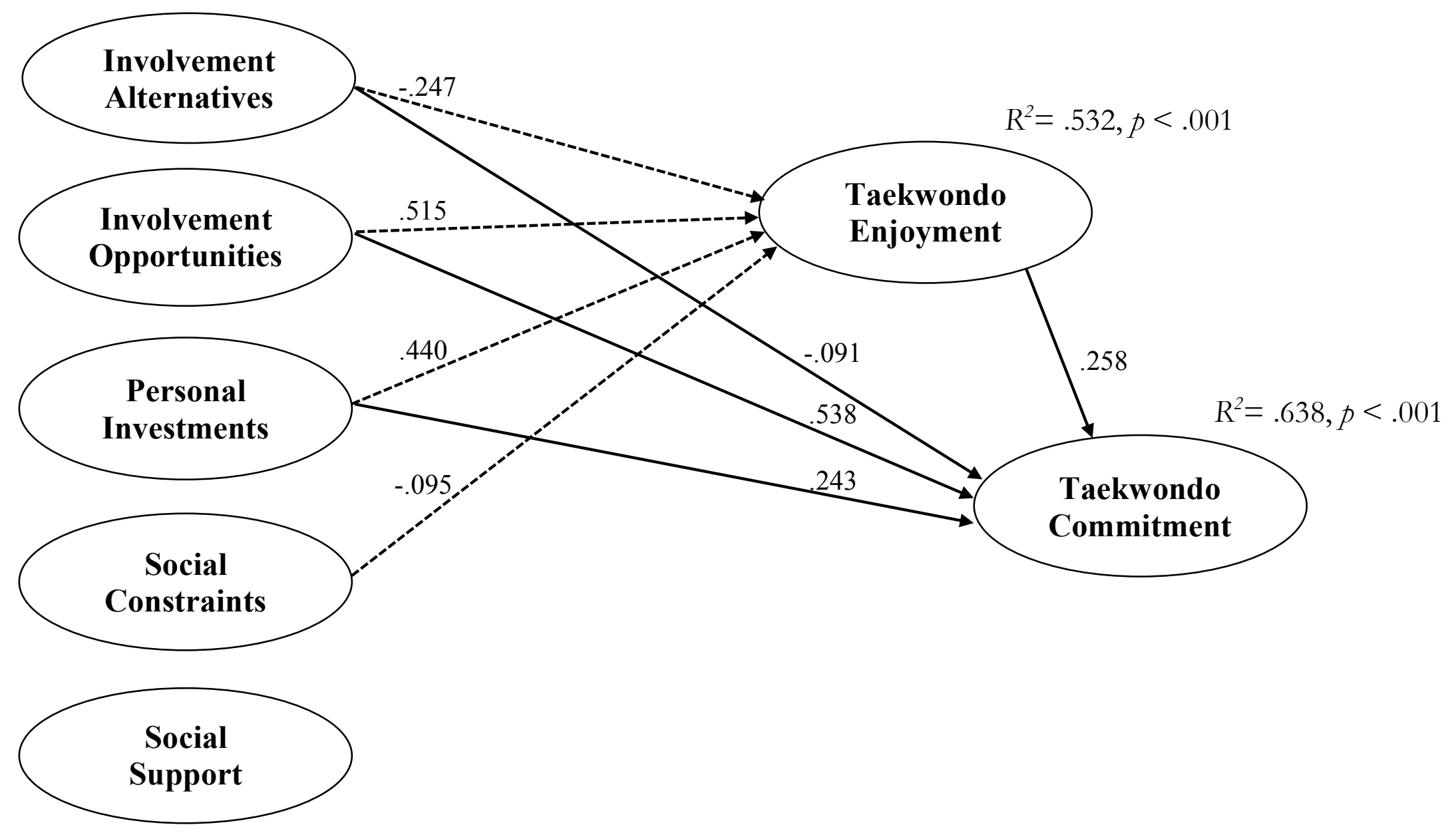


Figure 2

Youth Direct and Indirect Path Analysis

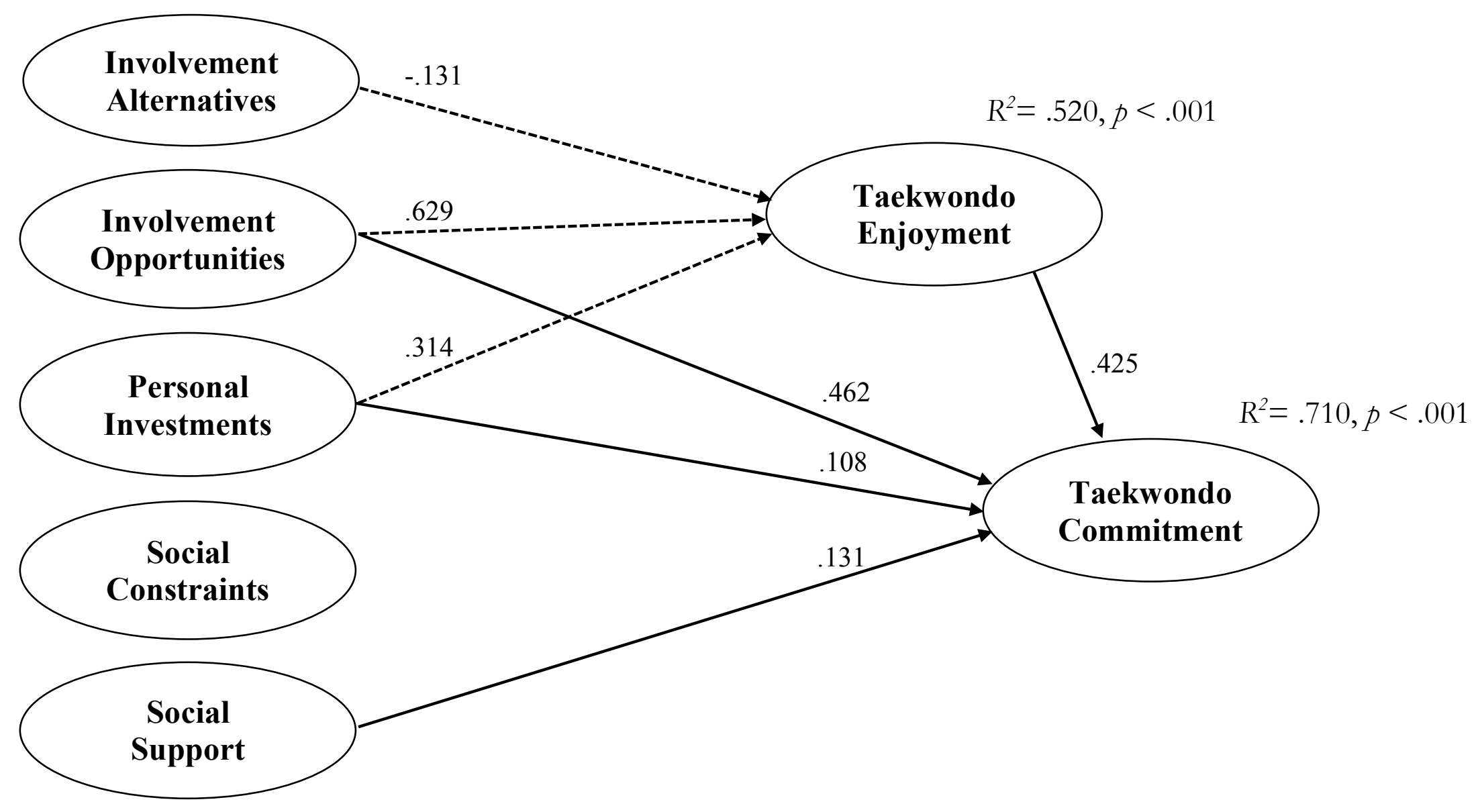

